\section{(A) Check for updates}

Cite this: Polym. Chem., 2021, 12 3177

\title{
RAFT polymerisation of renewable terpene (meth)acrylates and the convergent synthesis of methacrylate-acrylate-methacrylate triblock copolymers $\uparrow$
}

\author{
Rachel L. Atkinson, (D) ${ }^{a}$ Olivia R. Monaghan, ${ }^{a}$ Matthew T. Elsmore, ${ }^{b}$ \\ Paul D. Topham, (D) ${ }^{c}$ Daniel T. W. Toolan, (D) ${ }^{d}$ Matthew J. Derry, (D) ${ }^{c}$ \\ Vincenzo Taresco, (DD ${ }^{a}$ Robert A. Stockman, (D) a Davide S. A. De Focatiis, (D) ${ }^{b}$ \\ Derek J. Irvine (D) ${ }^{b}$ and Steven M. Howdle (D)*a
}

\begin{abstract}
Terpenes are ideal candidates for sustainable polymer feedstocks, due to their natural abundance and availability from existing waste streams. Previously, we have shown that a range of terpene(meth)acrylate monomers can be synthesised from the most commonly available terpenes ( $\alpha$-pinene, $\beta$-pinenene and limonene) and that these readily undergo radical polymerisation. We now report the synthesis of welldefined polymers and precise di- and multiblock copolymer architectures by use of RAFT control. A very wide range of $T_{\mathrm{g}}$ values are observed for the terpene (meth)acrylate homopolymers, from $-3{ }^{\circ} \mathrm{C}$ for poly (limonene acrylate), up to $+168^{\circ} \mathrm{C}$ for poly ( $\alpha$-pinene methacrylate), and we exploit these to create renewably-sourced hard-soft block copolymers. We also report the synthesis of difunctional poly $(\alpha-$ and $\beta$-pinene methacrylate) macro-RAFT agents and the preparation of ABA triblock copolymers. Promising adhesive properties are observed for a triblock copolymer comprised of poly( $\alpha$-pinene methacrylate) and poly(butyl acrylate) blocks. A range of fully terpene-based triblock copolymers containing poly(limonene acrylate) soft blocks are also reported.
\end{abstract}

Received 10th March 2021 Accepted 4th May 2021

DOI: $10.1039 / \mathrm{d} 1 \mathrm{py} 00326 \mathrm{~g}$ rsc.li/polymers myrcene, which was successfully polymerised via reversible addition-fragmentation chain transfer (RAFT) polymerisation up to $9000 \mathrm{~g} \mathrm{~mol}^{-1}$, though these reactions only reached low conversions after 3 days. ${ }^{3}$ Conversion was improved by increasing the temperature, but at the cost of increased branching and a broadening of the dispersity. ${ }^{4}$ RAFT copolymerisations of unmodified $\beta$-pinene with $n$-BuA, ${ }^{5}$ methyl acrylate ${ }^{6}$ and acrylonitrile $^{7}$ have also been reported, as have those of both limonene and $\beta$-pinene with various maleimides. ${ }^{8}$ Isoprene monomer has also been polymerised via free-radical methods to produce oligomers in greater than $40 \%$ yield, in this study both RAFT and catalytic chain transfer polymerisation (CCTP) methods were successfully applied., ${ }^{9,10}$

In many cases, functionalisation of monoterpenes has been found to increase their potential as monomers. Approaches have included the synthesis of ring structures, which can undergo ring-opening polymerisation (ROP),$^{11-14}$ or the addition of thiol groups to allow for polycondensation. ${ }^{15-17}$

Several terpene-based (meth)acrylate monomers have been reported, and were shown to undergo facile radical polymerisation. ${ }^{18}$ Sainz et al. described the addition of (meth)acrylate moieties to a terpene double bond via a two-step reaction, consisting of a hydroboration/oxidation step to produce an 


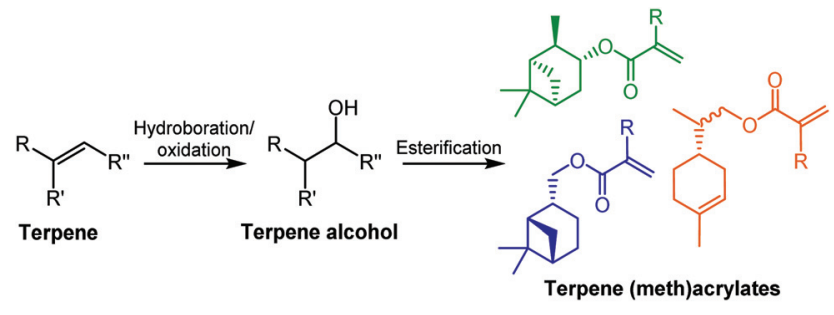

Scheme 1 General monomer synthesis reaction scheme and chemical structures of six terpene-based monomers produced by Sainz et al. ${ }^{18}$

alcohol intermediate, followed by an esterification (Scheme 1). An alternative route to the synthesis of terpene-derived acrylates was also developed, involving acrylic acid rather than the toxic acryloyl chloride, improving the overall sustainability of the monomer synthesis. More recently, a variety of options for improving the sustainability of the esterification step, for a range of existing terpenoids, have been highlighted by Droesbeke et $a{ }^{19}{ }^{19}$ A further study by Castagnet et al. has also reported the sustainable, enzyme-catalysed syntheses of terpene (meth)acrylates, utilising microwave irradiation. $^{20}$

Sainz et al. also demonstrated that the polymerisation of these terpene (meth)acrylate monomers could be influenced by varying the quantity of a chain transfer agent (CTA), dodecanethiol. ${ }^{18}$ High conversions and molecular weights ranging from 5000-32000 $\mathrm{g} \mathrm{mol}^{-1}$ were observed, depending on the CTA quantity. Each homopolymer exhibited a characteristic glass transition temperature $\left(T_{\mathrm{g}}\right)$ ranging from $0-145^{\circ} \mathrm{C}$ at the molecular weights obtained.

The addition of (meth)acrylate functionality also facilitates the use of reversible deactivation radical polymerisation (RDRP) techniques, such as RAFT, without the need for additional comonomers. The major advantage of using such RDRP techniques is the possibility of forming more complicated polymer architectures, such as (multi)block and star copolymers. $^{21,22}$

There have been a limited number of examples of the polymerisation of terpene (meth)acrylate homopolymers via RDRP. One approach is single-electron transfer living radical polymerisation (SET-LRP), used to polymerise both $\alpha$-pinene acrylate $^{23}$ and menthyl acrylate. ${ }^{24}$ More recently, RAFT polymerisation of terpene (meth)acrylates has also been investigated: Noppalit et al. reported the RAFT polymerisation of tetrahydrogeraniol acrylate ${ }^{25}$ and also the nitroxide mediated polymerisation (NMP) of tetrahydrogeraniol methacrylate. ${ }^{26}$ Additionally, Montanari et al. have produced a carvonederived, tetraol, acrylate monomer, which can be polymerised via RAFT to produce a hydrophilic polymer. ${ }^{27}$ This was then used in the synthesis of an amphiphilic block copolymer, incorporating a poly( $\beta$-pinene acrylate) hydrophobic block.

In this paper, we have developed the polymerisation of the previously reported, terpene-based monomers to produce more specialised, bio-based materials, with a focus on di- and triblock copolymers. Hard-soft block copolymers were targeted, in order to exploit the wide range of $T_{\mathrm{g}} \mathrm{s}$ exhibited by the poly[terpene (meth)acrylates]. Combining high $T_{\mathrm{g}}$ (hard) blocks with low $T_{\mathrm{g}}$ (soft) blocks should lead to a nanoscale, 3D network of hard and soft domains when phase separated. Such materials are desirable for self-healing, ${ }^{28}$ and shapememory polymer applications,${ }^{29}$ and are often used as additives to improve properties such as viscosity, ${ }^{30}$ and impact strength. ${ }^{31}$ ABA triblock copolymers, where A is a hard block and B is a soft block, have found uses as thermoplastic elastomers (TPEs) ${ }^{32}$ and pressure sensitive adhesives (PSAs), ${ }^{33}$ depending on their material properties.

\section{Results and discussion}

\section{RAFT polymerisation of terpene (meth)acrylates}

Initially, RAFT homopolymerisations of each of the six (meth) acrylate ((M)A) monomers were conducted using 2-cyano-2propyl dodecyl trithiocarbonate (CPDT) as the RAFT agent (Scheme 2), which is known to be compatible with both acrylates and methacrylates. ${ }^{34}$ Homopolymers with molecular weights of 5000 and $30000 \mathrm{~g} \mathrm{~mol}^{-1}$ were targeted, to determine whether RAFT can be used to control the polymerisation at both low and high molecular weights.

RAFT polymerisation of the terpene methacrylate monomers resulted in polymers with low molecular weight distributions and $M_{\mathrm{n}}$ values close to those targeted (Table 1). The RAFT polymerisation of both $\alpha$ PMA and $\beta$ PMA at $65^{\circ} \mathrm{C}$ demonstrated good RAFT control, with $Ð<1.3$ in all cases. A dispersity of less than 1.3 is indicative of a polymerisation proceeding via a controlled mechanism. ${ }^{35}$ For PLiMA, the refractive index GPC data showed a narrow peak, indicating good RAFT control. However, data from the light scattering detector showed the presence of a very small high molecular weight peak, (Fig. S1†) which could be due to PLiMA formed via uncontrolled free radical polymerisation, or a high molecular weight branched polymer indicating that the polymerisation was not fully controlled. A potential source of this branching is the cyclic double bond on the pendant group (Scheme 1).

The RAFT polymerisation of $\alpha \mathrm{PA}$ (at $M_{\mathrm{n}}=5000$ and $30000 \mathrm{~g}$ $\mathrm{mol}^{-1}$ ) with CPDT exhibited excellent control, with low dispersities $(<1.1)$ and the targeted $M_{\mathrm{n}} \mathrm{s}$ being achieved. $\beta$ PA polymerisation exhibited acceptable RAFT control when targeting $30000 \mathrm{~g} \mathrm{~mol}^{-1}$, with $M_{\mathrm{n}}$ and $D$ values slightly higher than desirable. But when targeting $5000 \mathrm{~g} \mathrm{~mol}^{-1}$, the P $\beta$ PA product was found to have significantly increased $M_{\mathrm{n}}$ and $Ð$ values.
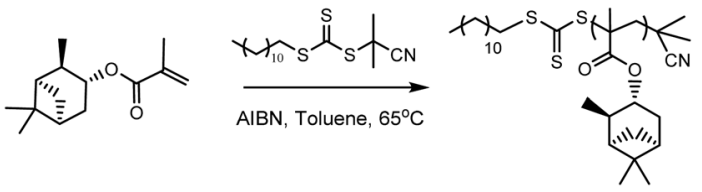

Scheme 2 aPMA polymerisation in the presence of CPDT as a RAFT agent. 
Table 1 Summary of results for the RAFT homopolymerisations of the terpene (meth)acrylate monomers

\begin{tabular}{|c|c|c|c|c|c|c|c|}
\hline Entry & Monomer & $\begin{array}{l}\text { Target } M_{\mathrm{n}} \\
\left(\mathrm{g} \mathrm{mol}^{-1}\right)\end{array}$ & $\begin{array}{l}\text { Conv. }^{a} \\
(\%)\end{array}$ & $\begin{array}{l}M_{\mathrm{n}}(\mathrm{th})^{b} \\
\left(\mathrm{~g} \mathrm{~mol}^{-1}\right)\end{array}$ & $\begin{array}{l}M_{\mathrm{n}}{ }^{c} \\
\left(\mathrm{~g} \mathrm{~mol}^{-1}\right)\end{array}$ & $\begin{array}{l}M_{\mathrm{w}}{ }^{c} \\
\left(\mathrm{~g} \mathrm{~mol}^{-1}\right)\end{array}$ & $\bigoplus^{c}$ \\
\hline 1 & $\alpha \mathrm{PMA}$ & 5000 & 97 & 4850 & 6100 & 8000 & 1.28 \\
\hline 2 & $\alpha \mathrm{PMA}$ & 30000 & 81 & 24300 & 18800 & 21900 & 1.17 \\
\hline 3 & $\beta \mathrm{PMA}$ & 5000 & 99 & 4950 & 6500 & 8000 & 1.22 \\
\hline 4 & $\beta \mathrm{PMA}$ & 30000 & 93 & 27900 & 28600 & 30700 & 1.05 \\
\hline 5 & LiMA & 5000 & 99 & 5000 & 5700 & 7200 & 1.14 \\
\hline 6 & LiMA & 30000 & 97 & 29100 & 20700 & 26700 & 1.29 \\
\hline 7 & $\alpha \mathrm{PA}$ & 5000 & 85 & 4250 & 4300 & 4700 & 1.10 \\
\hline 8 & $\alpha \mathrm{PA}$ & 30000 & 99 & 29700 & 28200 & 30400 & 1.08 \\
\hline 9 & $\beta \mathrm{PA}$ & 5000 & 91 & 4600 & 12400 & 20100 & 1.62 \\
\hline 10 & $\beta \mathrm{PA}$ & 30000 & 82 & 24600 & 30100 & 40800 & 1.35 \\
\hline 11 & LiA & 5000 & 90 & 4500 & 13800 & 38200 & 2.77 \\
\hline 12 & LiA & 30000 & 78 & 23400 & 39500 & 100000 & 2.53 \\
\hline 13 & LiA (DDMAT) & 30000 & 74 & 22200 & 58200 & 64700 & 3.20 \\
\hline
\end{tabular}

${ }^{a}$ Calculated by comparing integrals of monomer and polymer peaks in ${ }^{1} \mathrm{H}$ NMR. ${ }^{b}$ Calculated from conversion and target $M_{\mathrm{n}}{ }^{c}$ Measured by GPC. Each reaction was carried out over $24 \mathrm{~h}$ and used CPDT as the RAFT agent (except entry 13 which used DDMAT).

Finally, the RAFT homopolymerisation of LiA gave less promising results, with a dispersities above 2.5 at both high and low molecular weights, indicating that some branching or minor crosslinking may have occurred. As CPDT is known to be a more appropriate RAFT agent for methacrylates than acrylates, ${ }^{34}$ a LiA polymerisation reaction was also carried out using the RAFT agent 2-(dodecylthiocarbonothioylthio)-2methylpropionic acid (DDMAT), which has a less stable leaving group relative to CPDT and is therefore more suited to acrylate polymerisation. Surprisingly, we observed even poorer chain length control $\left(M_{\mathrm{n}}=60600 \mathrm{~g} \mathrm{~mol}^{-1}\right)$, a higher dispersity $(\theta=$ 3.20 ) and a maximum conversion of $74 \%$ was reached, even when the reaction was allowed to continue for 74 hours. The lack of control over the LiA polymerisation may also be due to branching, as described earlier.

\section{Terpene-derived hard-soft diblock copolymers}

The major benefit of using RDRP techniques such as RAFT, is that they can provide a route to a wide variety of polymer architectures and functionalities. An investigation was therefore carried out to determine if the terpene monomers could be chain extended from a previously synthesised macro-RAFT agent, using the well-understood poly(methyl methacrylate) PMMA as the first block. PMMA macro-RAFT agents ( $c a$. $15000 \mathrm{~g} \mathrm{~mol}^{-1}, D<1.2$ ) were reinitiated in the presence of each of the six terpene-based monomers, (Scheme 3) with target $M_{\mathrm{n}}$ values of $15000 \mathrm{~g} \mathrm{~mol}^{-1}$ for the second block. All three methacrylate monomers were shown to have grown in a controlled manner, to produce diblock copolymers with molecular weights close to the targeted values and $D<1.3$ (Table S1 and Fig. S2 $\dagger$ ). Additionally, it was found that $\alpha \mathrm{PA}$ also produced a reasonably well-controlled diblock copolymer with $D=$ 1.31. $\beta$ PA exhibited an increased $D=1.48$, caused by the low molecular weight shoulder peak which indicated the presence of some dead chains.

In the case of LiA, the use of a PMMA-macro RAFT agent led to a remarkable improvement in the RAFT control of the polymerisation (Fig. S2 $\dagger$ ). Chain extension of PMMA with LiA was well-controlled, resulting in a diblock copolymer with $D=$ 1.28 , though the conversion remained low at only $65 \%$. The successful diblock copolymer syntheses confirmed that each of the terpene (meth)acrylate monomers has the potential to be used in the synthesis of block copolymers.

However, commercial MMA production is currently not considered to be sustainable, ${ }^{36}$ therefore the synthesis of fully renewable diblock copolymers is preferred. RAFT polymerisation has therefore been used to synthesise renewable, terpene-derived block copolymer architectures, with a focus on combining hard and soft blocks. The very wide range of $T_{\mathrm{g}} \mathrm{s}$ observed for these poly[terpene (meth)acrylates] allows for the synthesis of fully terpene-derived, hard-soft diblock copolymers. The $T_{\mathrm{g}} \mathrm{s}$ for each of the homopolymers measured by DMA are highlighted (Table 2).

Some of these $T_{\mathrm{g}}$ values are slightly higher than those reported by Sainz et al. ${ }^{18}$ This is because some of the polymers had higher molecular weights and additionally, the materials
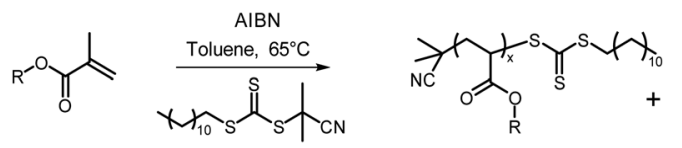<smiles>[R]OC(=O)C=C</smiles>

$\stackrel{\text { Toluene, } 65^{\circ} \mathrm{C}}{\longrightarrow}$

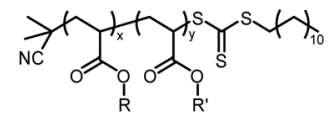

$\mathrm{R}=\mathrm{CH}_{3}$, terpene

$\mathrm{R}^{\prime}=$ terpene

Scheme 3 General synthesis of a polymethacrylate- $b$-polyacrylate diblock copolymer using the RAFT agent CPDT. 
Table $2 T_{\mathrm{g}}$ data for each of the terpene (meth)acrylate homopolymers at the highest molecular weights tested. Further data can be found in Table S2†

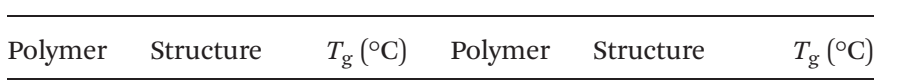

PoPMA

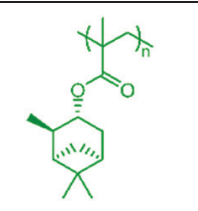

168

PßPMA

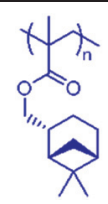

84

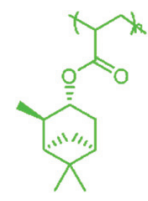

PLiMA

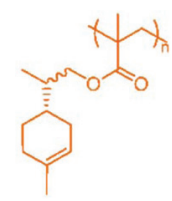

51

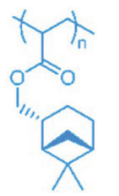

41

PLiA

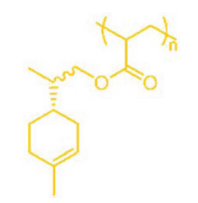

To create these block copolymers, macro-RAFT agents of P $\alpha$ PMA and P $\beta$ PMA were required. The previous P $\alpha$ PMA and P $\beta$ PMA homopolymers were obtained after $24 \mathrm{~h}$ of polymerisation at $65{ }^{\circ} \mathrm{C}$, when the reaction had reached full conversion. However, in order to retain chain-end fidelity and thus ensure that the polymer can be reinitiated and chain extended. It is preferable to stop the polymerisation at well below full conversion, before any significant chain termination has occurred. ${ }^{40}$ Some methods of RAFT polymerisation have been optimised to chain extend effectively up to $100 \%$ conversion, ${ }^{41,42}$ but for solution polymerisation of these previously untested monomers, it was found that taking $60 \%$ conversion as an upper limit was the most reliable method of ensuring chain end fidelity.

The $\beta$ PMA polymerisation targeting an $M_{\mathrm{n}}$ of 30000 $\mathrm{g} \mathrm{mol}^{-1}$ at $65{ }^{\circ} \mathrm{C}$ consistently reached $60 \%$ conversion, equating to $18000 \mathrm{~g} \mathrm{~mol}^{-1}$ in 4-6 hours, with low dispersities. For the equivalent $\alpha$ PMA polymerisation, reproducibility was an issue; initially, the $\alpha$ PMA polymerisation would reach $60 \%$ between 5-8 h, however some polymerisations would take much longer, exhibiting an extended initiation period of several hours, where no polymer was formed. It was found that increasing the reaction temperature to $75^{\circ} \mathrm{C}$ eliminated this issue, and at this temperature, well-defined P $\alpha$ PMA homopolymers were reliably produced in 2.5-3 hours.

Initially, P $\alpha$ PMA macro-RAFT agents were chain extended with $\beta \mathrm{PA}$ and LiA, (Table 3). Chain extension of P $\alpha$ PMA with $\beta$ PA produced a polymer with a $D<1.3$ and the desired molecular weight; GPC data (Fig. 2a) show that the peak is slightly broadened relative to the P $\alpha$ PMA peak, suggesting some minor loss of control over the block copolymer synthesis.

LiA chain extension of $c a .10000 \mathrm{~g} \mathrm{~mol}^{-1}$ resulted in a welldefined diblock copolymer (PoPMA- $b$-PLiA1, Fig. $1 \mathrm{~b}$ and Table 3). A longer LiA chain extension of $18000 \mathrm{~g} \mathrm{~mol} \mathrm{~m}^{-1}$ showed increased dispersity, indicating chain growth was progressing a less controlled manner (P $\alpha$ PMA- $b$-PLiA2, Table 3), but $D=1.61$ is still much lower than that obtained for LiA homopolymerisation.

Subsequently, chain extension of the P $\beta$ PMA macro-RAFT agent was investigated. The $T_{\mathrm{g}}$ of $\beta \mathrm{PMA}$ at $121{ }^{\circ} \mathrm{C}$ is lower than that of $\alpha$ PMA at $168^{\circ} \mathrm{C}$, and could offer lower processing temp-

Table 3 Summary of results obtained for hard-soft block copolymers

\begin{tabular}{|c|c|c|c|c|c|c|c|c|c|}
\hline Code & $\begin{array}{l}\text { Macro-RAFT } \\
(\mathrm{B} 1)^{a}\end{array}$ & $\begin{array}{l}M_{\mathrm{n}}(\mathrm{B} 1)^{b} \\
\left(\mathrm{~g} \mathrm{\textrm {mol } ^ { - 1 }}\right)\end{array}$ & $\begin{array}{l}\text { Monomer } \\
\text { (B2) }\end{array}$ & $\begin{array}{l}\text { Target } M_{\mathrm{n}} \mathrm{B} 2 \\
\left(\mathrm{~g} \mathrm{~mol}^{-1}\right)\end{array}$ & $\begin{array}{l}\text { Conv. }{ }^{c} \\
(\%)\end{array}$ & $\begin{array}{l}M_{\mathrm{n}}(\mathrm{th})^{d} \\
\left(\mathrm{~g} \mathrm{~mol}^{-1}\right)\end{array}$ & $\begin{array}{l}M_{\mathrm{n}}{ }^{b} \\
\left(\mathrm{~g} \mathrm{~mol} \mathrm{~mol}^{-1}\right)\end{array}$ & $\begin{array}{l}M_{\mathrm{w}}{ }^{b} \\
\left(\mathrm{~g} \mathrm{~mol}^{-1}\right)\end{array}$ & $\bigoplus^{b}$ \\
\hline Р $\alpha$ PMA- $b-\mathrm{P} \beta \mathrm{PA}$ & P $\alpha$ PMA1 & 19000 & $\beta \mathrm{PA}$ & 19000 & 77 & 32000 & 29500 & 38100 & 1.29 \\
\hline P $\alpha$ PMA- $b$-PLiA1 & P $\alpha$ PMA2 & 18500 & LiA & 18500 & 55 & 28700 & 33800 & 43000 & 1.27 \\
\hline P $\alpha$ PMA- $b$-PLiA2 & P $\alpha$ PMA2 & 18500 & LiA & 29200 & 63 & 36900 & 36700 & 59000 & 1.61 \\
\hline Р $\beta$ РМА- $b-\mathrm{P} \beta \mathrm{PA}$ & Р $\beta$ PMA1 & 22100 & $\beta \mathrm{PA}$ & 16000 & 88 & 36200 & 38300 & 53900 & 1.41 \\
\hline P $\beta$ PMA- $b$-PLiA1 & Р $\beta$ РМА2 & 24100 & LiA & 24100 & 54 & 37000 & 34400 & 43200 & 1.25 \\
\hline Р $\beta$ PMA- $b$-PLiA2 & Р $\beta$ РМA2 & 24100 & $\mathrm{LiA}$ & 42100 & 69 & 52100 & 56600 & 109800 & 1.94 \\
\hline
\end{tabular}

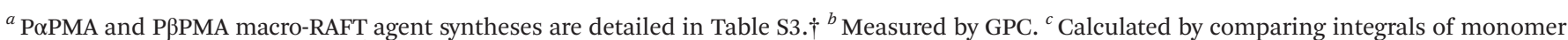

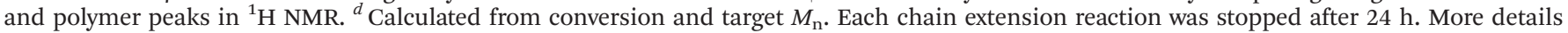
on the macro-RAFT agent syntheses can be found in Table S3. $\dagger$ 
a)
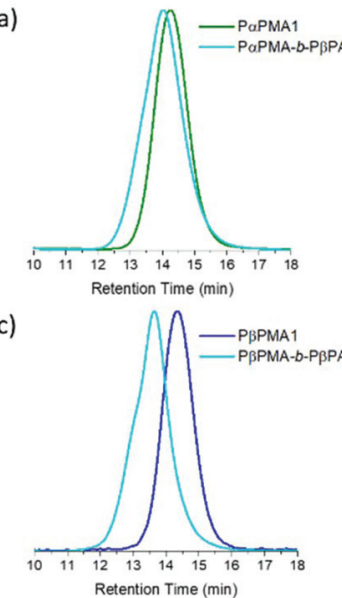

e)

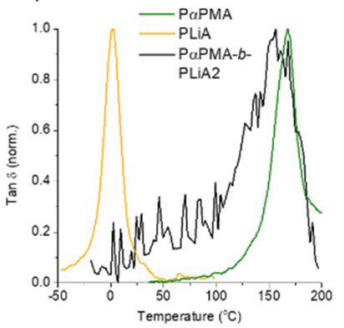

f)

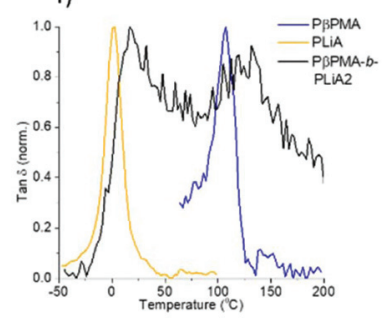

Fig. 1 (a-d) GPC traces showing controlled chain extension of P $\alpha$ PMA with (a) $\beta P A$ and (b) LiA, and of P $\beta P M A$ with (c) $\beta P A$ and (d) LiA. (e and f) DMA traces for (d) P $\alpha$ PMA- $b$-PLiA2 and (e) P $\beta P M A-b$-PLiA2, overlaid with the DMA traces of the relevant homopolymers (synthesised to full conversion).

eratures which may be preferred for an application where a very high $T_{\mathrm{g}}$ is not required. Note that this value is still higher than the $T_{\mathrm{g}}$ of petroleum-derived polystyrene at $100{ }^{\circ} \mathrm{C}$, a hugely popular polymer used in TPE synthesis. Polystyrenebased triblock copolymers such as polystyrene-block-polybutadiene-block-polystyrene (SBS), have dominated the TPE market for over 50 years. $^{43}$

LiA and $\beta$ PA were also chain extended from a P $\beta$ PMA macro-RAFT agent. GPC results suggest that the chain extension of P $\beta$ PMA with $\beta \mathrm{PA}$ was less well-controlled than for PoPMA. The dispersity was increased slightly to $D=1.41$, though the targeted $M_{\mathrm{n}}$ was achieved. This can also be observed as a high molecular weight shoulder peak in the GPC trace (Fig. 1c). However, chain extension of P $\beta$ PMA with LiA to ca. $13000 \mathrm{~g} \mathrm{~mol}^{-1}$ proceeded in a similarly well-controlled fashion as for PoPMA, with $D=1.25$ (P $\beta$ PMA- $b$-PLiA1, Table 3). Again, a longer chain extension with LiA $\left(28000 \mathrm{~g} \mathrm{~mol}^{-1}\right)$ did not occur in a well-controlled manner and only broad dispersity was achieved (PßPMA- $b$-PLiA2, Table 3 ).

DMA results were obtained for each of the diblock copolymers; for those containing a P $\beta$ PA soft block only one peak was observed, indicating a lack of phase separation. This miscibility is likely due to the similarity in the pendant groups of the hard and soft blocks. However, some phase separation was

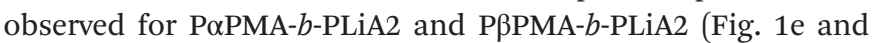

f). In the case of P $\beta$ PMA- $b$-PLiA2, two peaks can clearly be seen in the DMA trace, relating to the $T_{\mathrm{g}} \mathrm{s}$ of the hard and soft blocks. The DMA trace for PoPMA- $b$-PLiA shows a peak that clearly corresponds to the PoPMA hard block. Unusually, a low $T_{\mathrm{g}}$ peak is not seen, though there is a considerable amount of noise in that region. According to the Fox equation: ${ }^{44}$

$$
\frac{1}{T_{\mathrm{g}}}=\frac{w_{1}}{T_{\mathrm{g}, 1}}+\frac{w_{2}}{T_{\mathrm{g}, 2}}
$$

where $\omega_{1}$ and $\omega_{2}$ refer to the volume fractions of the hard and soft blocks respectively, with $T_{\mathrm{g}, 1}$ and $T_{\mathrm{g}, 2}$ being the corresponding glass transition temperatures for the individual components. If this polymer were fully miscible, a single peak at $66{ }^{\circ} \mathrm{C}$ would be expected and this is clearly not the case, indicating that some phase separation has occurred. These observations suggest that such combinations of hard and soft block may be applicable for thermoplastic elastomer applications.

Overall, we have screened these monomers, which had not previously been polymerised via RAFT, to show that well defined polymers can be prepared for the majority of the terpene-based monomers. However, the lack of control over the PLiA homopolymerisation and higher molecular weight chain extensions limit its usefulness. Further work to improve the RAFT control of LiA is required if this is to be an easily accessible soft block.

\section{ABA triblock copolymers}

ABA triblock copolymers are a particularly useful form of hard-soft block copolymer, as they have the potential to exhibit elastomeric properties ${ }^{45}$ and could act as thermoplastic elastomers (TPEs). TPEs with an ABA triblock copolymer structure, incorporating hard methacrylate and soft acrylate blocks, are only effective in the form polymethacrylate-block-polyacrylate-block-polymethacrylate (i.e. hard-soft-hard), as the soft, central block must bridge two hard domains. This means that it is necessary to use a Z-connected, difunctional RAFT agent, which will synthesise the outer, polymethacrylate blocks first; a method known as a convergent chain growth. ${ }^{39}$ Unfortunately, there are not currently any commercially available RAFT agents of this type that exhibit good RAFT control over methacrylate polymerisation. $S, S$-Dibenzyl trithiocarbonate (DBTTC), the most commonly used difunctional RAFT agent, is not suitable for use with methacrylates, due to insufficient radical stabilisation of the leaving groups. ${ }^{46}$

The difunctional RAFT-agent $S, S^{\prime}$-bis $\left(\alpha, \alpha^{\prime}\right.$-dimethylacetic acid)trithiocarbonate (BDAT) is a Z-connected RAFT agent that is typically more suited to acrylate polymerisation than methacrylate, but it has been shown to provide some control over MMA polymerisation under certain conditions. ${ }^{47}$ The reported PMMA was synthesised with higher than expected molecular weights, due to an initial uncontrolled period, but after around 10 minutes the polymerisation became controlled and a linear proportionality for $M_{\mathrm{n}}$ as a function of conversion was observed. We have investigated this approach using the terpene methacrylate monomers, speculating that BDAT may 

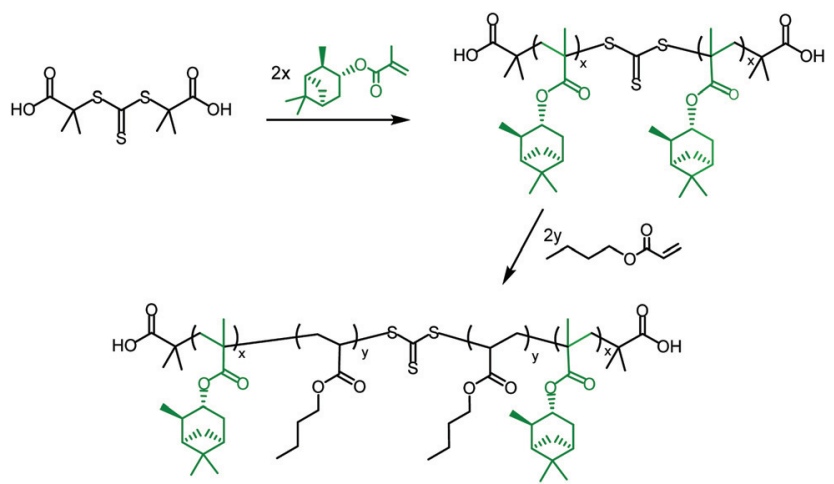

Scheme 4 General synthesis of a P $\alpha$ PMA- $b-\mathrm{PBuA}-b-\mathrm{P} \alpha \mathrm{PMA}$ triblock copolymer in two steps, using the RAFT agent BDAT.

provide sufficient control over the $\alpha$ PMA polymerisation to permit the synthesis of triblock copolymers. Initial studies focused on using P $\alpha$ PMA as the hard block (Scheme 4).

BDAT was used to synthesise difunctional macro-RAFT agents of P $\alpha$ PMA. Initial attempts resulted in $D=1.5-1.8$, suggesting that these polymerisations were not fully RAFT-controlled. The molecular weight was also higher than expected in all cases, often reaching around double the predicted molecular weight, and the relationship to conversion was not consistent (Table $\mathrm{S} 4 \dagger$ ).

To assess the level of RAFT chain end fidelity in the P $\alpha \mathrm{PMA}$ produced in this way, a chain extension reaction was carried out using PBuA, a very commonly used soft block for acrylic TPEs $^{48-50}$ with $T_{\mathrm{g}}$ of $c a .-50{ }^{\circ} \mathrm{C}$. P $\alpha$ PMA was reinitiated in the presence of BuA and the polymerisation reached 95\% conversion by ${ }^{1} \mathrm{H}$ NMR. Somewhat surprisingly, GPC results showed that the chain extension occurred in a reasonably well-controlled manner, to produce a P $\alpha \mathrm{PMA}-b$-PBuA- $b$-P $\alpha \mathrm{PMA}$ triblock copolymer, $74 \mathrm{~kg} \mathrm{~mol}{ }^{-1}, 23 \mathrm{wt} \%$ hard block (denoted as $\alpha \mathrm{B} \alpha-74-23)$. The polymer exhibited a minor low molecular weight shoulder peak, but no significant increase in dispersity was observed (Fig. 2a) suggesting reasonably good RAFT chain end fidelity of the P $\alpha$ PMA macro-RAFT agent.

Despite the apparent control issues during the macro-RAFT agent synthesis, it seems very possible that polymethacrylateblock-polyacrylate-block-polymethacrylate triblock copolymers can be produced successfully via this convergent RAFT method; the slight loss in molecular weight control in the first step being outweighed by the utility of this new approach. The good RAFT control and high conversion observed in the second step means that it is still possible to target specific molar ratios of blocks and should allow access to specific phase separated morphologies.

As discussed earlier, $\beta$ PMA may also prove viable as a hard block, with a $T_{\mathrm{g}}$ of $121^{\circ} \mathrm{C}$. This lower value could allow significantly lower processing temperatures and may therefore be preferable for applications where extreme temperatures will not be required. A number of $\beta$ PMA homopolymerisations were carried out using BDAT as the RAFT agent. As was seen for the equivalent $\alpha$ PMA polymerisations, higher than

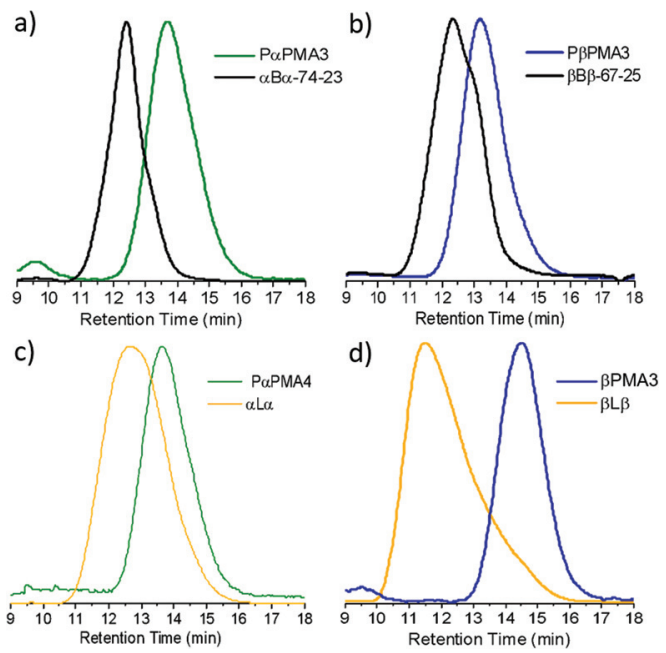

Fig. 2 GPC traces for the chain extension of (a) PoPMA with BuA, (b) P $\beta$ PMA with BuA, (c) P $\alpha$ PMA with LiA and (d) P $\beta P M A$ with LiA. Details for the syntheses of each of the macro-RAFT agents can be found in Table S6. $†$

expected molecular weights were observed, as were dispersities above 1.4 (Table S5†)

Two P $\beta$ PMA macro-RAFT agents were chain extended with PBuA to produce P $\beta$ PMA- $b$-PBuA- $b$-P $\beta$ PMA triblock copolymers: $\beta B \beta-67-25$ (Fig. $2 b$ and Table 4 ) and $\beta B \beta-38-23$ (Fig. S3 and Table $\mathrm{S} 7 \dagger)$. The targeted $\mathrm{PBuA}$ molecular weights for these block copolymers were 50000 and $30000 \mathrm{~g} \mathrm{~mol}^{-1}$ respectively, and both reactions reached high conversions. The GPC traces for each polymer clearly show that chain extension has occurred, but a low molecular weight shoulder peak can be observed in both cases, indicating the presence of some dead chains and causing a slight increase in the dispersity.

The limonene acrylate polymer has the lowest $T_{\mathrm{g}}$ of all the terpene acrylates, at $-3{ }^{\circ} \mathrm{C}$. PLiA was therefore most promising as a soft block for the synthesis of a fully terpene-derived triblock copolymer. However, LiA homopolymerisation was not well controlled via RAFT, but chain extension from a polymethacrylate macro-RAFT agent gave significantly improved results. To take advantage of this, macro-RAFT agents of

Table 4 Molecular weight and dispersity data for ABA triblock copolymers containing P $\beta$ PMA hard blocks and PLiA soft blocks

\begin{tabular}{|c|c|c|c|}
\hline Polymer & $\begin{array}{l}M_{\mathrm{n}}(\text { block } 1) / Ð^{a} \\
\left.(\mathrm{~kg} \mathrm{~mol})^{-1}\right)\end{array}$ & $\begin{array}{l}M_{\mathrm{n}}(\text { triblock }) / Ð^{a} \\
\left(\mathrm{~kg} \mathrm{~mol}{ }^{-1}\right)\end{array}$ & $\begin{array}{l}\text { wt\% (block 1) } \\
(\mathrm{NMR})^{b}\end{array}$ \\
\hline$\alpha \mathrm{B} \alpha-74-23$ & $17 / 1.58$ & $74 / 1.31$ & 23 \\
\hline$\beta B \beta-67-25$ & $17 / 1.52$ & $55 / 1.38$ & $25^{c}$ \\
\hline$\alpha \operatorname{L} \alpha$ & $16 / 1.56$ & $46 / 2.01$ & 45 \\
\hline$\beta \mathrm{L} \beta$ & $9 / 1.47$ & $21 / 3.21^{d}$ & \\
\hline
\end{tabular}

${ }^{a}$ Measured by GPC. ${ }^{b}$ Calculated from ${ }^{1} \mathrm{H}$ NMR. ${ }^{c}$ Taken from wt $\%$ reagents added as $>96 \%$ conv. ${ }^{d}$ Complete overlap of ${ }^{1} \mathrm{H}$ NMR polymer peaks - GPC column calibration used as wt $\%$ could not be obtained. More detailed results for these polymerisations can be found in Tables S6 and S7.† 
P $\alpha$ PMA and P $\beta$ PMA were chain extended with LiA, leading to hard-soft-hard, renewably sourced triblock copolymers. Although the LiA polymerisation step did not reach full conversion, stopping at $60-70 \%$ for both chain extensions, it was clear that the peak had shifted to lower retention times. In the case of $\alpha \mathrm{L} \alpha$, the peak is broadened $(\nexists=2.01$, Table 4) compared to the macro-RAFT agent, but is still symmetrical. This suggests reasonably good chain end fidelity, as no significant low molecular weight tailing is observed (Fig. 2c), but a lack of control and potentially some branching occurs during the chain extension step. For $\beta L \beta$, the peak has again shifted to lower retention times, but with significant low molecular weight tailing (Fig. 2d). This indicates a loss of both control over the LiA chain extension and RAFT chain end fidelity in the macro-RAFT agent which might introduce some homopolymer in the material and this could be detrimental to its elastic recovery. However, additional block A homopolymer (P $\beta \mathrm{PMA})$ may be less of a concern than additional block B homopolymer (PLiA), since block B is the bridging chain between hard domains.

The chain extension with BuA has proved the most successful. While some LiA chain extension has occurred, the low conversions and high dispersities mean that PLiA needs further optimisation to be investigated fully for use in a TPE. However, we have shown that it is possible to synthesise polymethacrylate-block-polyacrylate-block-polymethacrylate triblock copolymers via a convergent RAFT polymerisation method, with some sacrifice of the dispersity and molecular weight control of the first methacrylate polymerisation. For the remainder of this work, we focus on the behaviour and potential applications of the P $\alpha \mathrm{PMA}-b$-PBuA- $b$-P $\alpha \mathrm{PMA}(\alpha \mathrm{B} \alpha)$ materials.

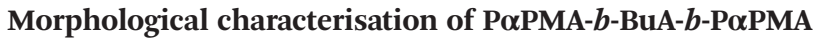 $(\alpha \mathbf{B} \alpha)$}

Four $\alpha \mathrm{B} \alpha$ triblock copolymers were synthesised, each with varying wt $\%$ of hard block (Table 5 ). No significant dispersity increase was observed for each BuA chain extension, though again, some minor low molecular weight shoulder peaks can be seen (Fig. S4 $\dagger$ ). For a series of polymers having the same hard and soft blocks we would expect an increase in the ratio of hard polymer to soft polymer to have a significant effect on the tensile properties of the material. ${ }^{51}$

AFM studies have been performed on each $\alpha \mathrm{B} \alpha$ triblock copolymer to explore the phase-separated morphologies (Fig. 3). $\alpha \mathrm{B} \alpha-74-23$ displayed a morphology consisting of small, hard domains with the soft block as the matrix phase. Such a
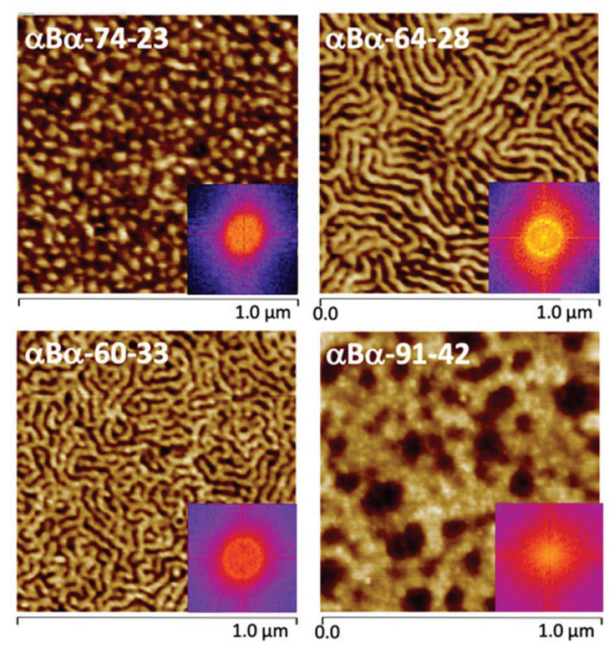

Fig. 3 AFM images for each of the synthesised $\alpha \mathrm{B} \alpha$ triblock copolymers (height images), with FFTs shown as an insert. $1 \times 1 \mu \mathrm{m}$ area shown. Lighter areas correspond to the P $\alpha \mathrm{PMA}$ domains and darker regions correspond to the PBuA domains.

morphology is indicative of being within the spherical or cylindrical regions of the thermodynamic phase diagram. Such morphologies are desirable for TPEs, as the small domains act as physical crosslinks, while still allowing the soft PBuA matrix to be reasonably mobile. ${ }^{45}$ A dominant length scale of $33 \mathrm{~nm}$ was determined for $\alpha \mathrm{B} \alpha-74-23$, by taking the Fast Fourier Transform (FFT) of the AFM image (Fig. 3). Other samples, $\alpha \mathrm{B} \alpha-64-28$ and $\alpha \mathrm{B} \alpha-60-33$, also showed well-defined, phase separated morphologies with dominant length scales of 41 and $38 \mathrm{~nm}$, respectively. $\alpha \mathrm{B} \alpha-64-28$ appears to have adopted a lamellar type morphology, which may be attributed to either lamellae perpendicularly orientated to the substrate surface or cylinders orientated parallel to the substrate surface. $\alpha \mathrm{B} \alpha-60$ 33 showed a similar morphology, but the increased hard polymer content is apparent in the AFM image. Some areas appear to show an inverse cylindrical-type morphology, where soft domains are dispersed in a hard polymer matrix; the opposite of the desired morphology. Finally, $\alpha \mathrm{B} \alpha-91-42$ showed the least well-defined morphology of the four $\alpha \mathrm{B} \alpha$ triblock copolymers, and appears to be fully comprised of large soft domains within a hard matrix.

AFM analysis of the phase separated morphologies of the four $\alpha \mathrm{B} \alpha$ triblock copolymers are highly surface sensitive, due to both the nature of AFM measurements and the intricacies

Table 5 Molecular weight and dispersity data for ABA triblock copolymers P $\alpha$ PMA- $b-\mathrm{PBuA}-b-\mathrm{P} \alpha \mathrm{PMA}$ of varying $M_{\mathrm{n}}$ and wt\%

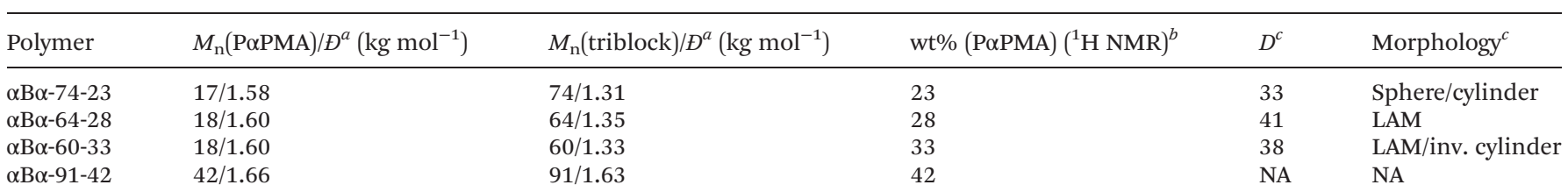

${ }^{a}$ Measured by GPC. ${ }^{b}$ Calculated from ${ }^{1}$ H NMR data. ${ }^{c}$ Measured by AFM. Additional data for these polymerisations can be found in Table S7, ESI. $\dagger$ 
of thin-film processing in determining morphological evolution towards thermodynamic equilibrium. Complementary small-angle X-ray scattering (SAXS) experiments were performed on bulk, solvent cast samples to provide further insights into the nanoscale behaviour of the $\alpha \mathrm{B} \alpha$ triblock copolymers (Fig. S5†). The SAXS patterns clearly indicate microphase separation in each of the triblock copolymers, but there is insufficient order to be conclusive about the morphology assignment. Tentatively, the $\alpha \mathrm{B} \alpha-74-23$ triblock copolymer appears to show lamellar morphology (a second peak is observed at $2 \mathrm{q}^{*}$, where $\mathrm{q}^{*}$ is the primary scattered peak). However, this assignment does not match with that expected for a block copolymer containing $23 \mathrm{wt} \%$ of the minor component, where a spherical or cylindrical morphology would be expected (as shown in the AFM), and we cannot rule out the presence of additional peaks (e.g. at $\sqrt{2}$ and $\sqrt{ } 3$ for bcc spheres or $\sqrt{ } 3$ for hexagonally packed cylinders) between the relatively broad peaks that are clearly observed. We can conclude that both AFM and SAXS demonstrate that the $\alpha \mathrm{B} \alpha-[74-$ 23, 64-28 and 91-42] triblock copolymers form phase separated nanomorphologies. Clearly, contributions of both sample processing and the specificity of the morphological technique employed (e.g. surface vs. bulk) indicate that these polymers exhibit complex phase behaviour and these will be the subject of future detailed investigations.

\section{Tensile and adhesive properties of an $\alpha$-pinene-based pressure sensitive adhesive (PSA)}

The previous AFM measurements have demonstrated that $\alpha B \alpha-74-23$ is capable of forming a desirable morphology for use as a TPE: discrete hard domains dispersed within a soft matrix, so this material was taken forward for mechanical characterisations. Tensile measurements were carried out with engineering stress $(\sigma)$ and strain $(\varepsilon)$ being reported for ease of comparison with tensile data from other sources (Table 6). The averaged tensile data (Fig. 4 - circles) shows up to $\varepsilon=300 \%$ for 8 specimens of $\alpha \mathrm{B} \alpha-74-23$, with an average thickness of $0.623 \pm$ $0.028 \mathrm{~mm}$, where \pm represents one standard error. Excellent repeatability between specimens was found up to $\sim 100 \%$ strain, above which some deviation occurs. An average ultimate tensile strain $\left(\varepsilon_{\text {UTS }}\right)$, defined as the strain at the ultimate tensile stress $\left(\sigma_{\mathrm{UTS}}\right)$, exceeding $500 \%$ was measured for $\alpha \mathrm{B} \alpha-74$ 23 (Table 6) at a $\sigma_{\text {UTS }}$ of $722 \mathrm{kPa}$. This behaviour is typical of polyacrylate materials which generally exhibit a higher chain entanglement length than some other typically used soft blocks (such as polybutadiene or polyisoprene), which in turn reduces the density of entanglements in the soft matrix. ${ }^{52}$

The films of $\alpha \mathrm{B} \alpha-74-23$ used in the tensile measurements were observed to adhere well to many substrates, and the tack

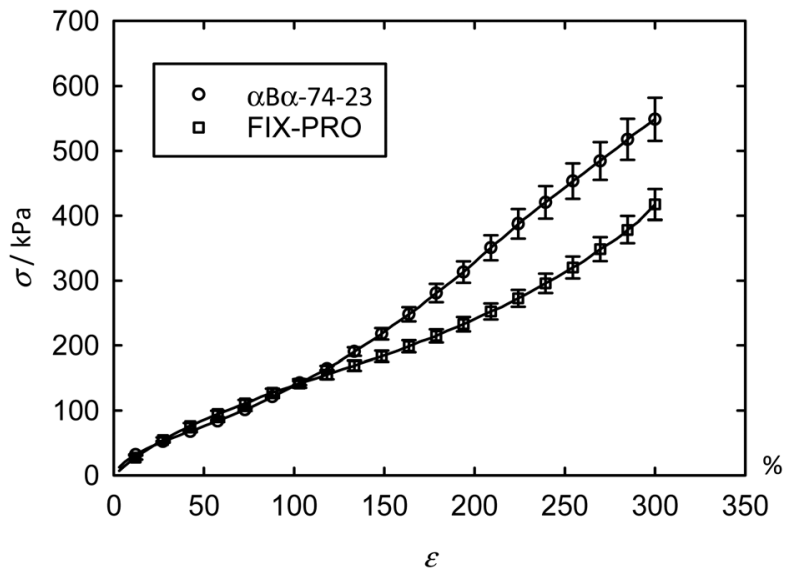

Fig. 4 Average tensile performance for $\alpha \mathrm{B} \alpha-74-23$ and FIX-PRO ${ }^{\circledR}$ are given as squares and circles respectively, showing similar tensile performance up to $120 \%$ strain. Error bars denoting \pm one standard error at symbols are given for clarity, with lines through data representing the full curve in each case.

was observed to be lasting. This is not surprising as this type of soft, acrylic TPE material is well-suited for use as a PSA, and can offer improvement over some of the more common types. It is known that soft, acrylic polymers behave well as PSAs, ${ }^{56-58}$ however these typically require a cross-linked chemical structure to prevent creep, making them difficult to reprocess and recycle. A number of materials of this type have been synthesised from terpene (meth)acrylate monomers. Examples of this include tetrahydrogeraniol acrylate-based polymers from Baek et al., one combined with menthyl acrylate, ${ }^{59}$ and a separate combined with isobornyl methacrylate. ${ }^{60} \mathrm{~A}$ recent paper by Droesbeke et al. has utilised tetrahydrogeraniol, citronellol, menthol and isoborneol (meth)acrylate monomers, in the emulsion polymerisation of waterborne PSAs. ${ }^{61}$

TPE triblock copolymers such as SBS offer a recyclable alternative, however, for these materials to be useful as PSAs, they require the addition of a tackifier to induce sufficient wettability to a substrate and improve adhesive performance. ${ }^{62}$

Alternatively, the polyterpene acrylic TPE we have developed can be effectively melted or dissolved and reprocessed, and the low modulus and high wettability of the acrylic polymers eliminate the need for any additional tackifier. Furthermore, polyterpene resins are desirable for use in adhesives due to their intrinsic tackiness and have found application as tack modifiers in hot melt and pressure sensitive adhesives for this reason. ${ }^{63}$

To assess the potential application as a PSA, the mechanical properties of the novel material were compared to those of a

Table 6 Summary of tensile performance for $\alpha \mathrm{B} \alpha-74-23$ and FIX-PRO®, where \pm denotes one standard error

\begin{tabular}{|c|c|c|c|c|c|c|c|}
\hline Material & $\sigma_{\text {UTS }}(\mathrm{kPa})$ & $\varepsilon_{\text {UTS }}(\%)$ & $E_{\mathrm{s}}$ at $1 \%(\mathrm{kPa})$ & $E_{\mathrm{s}}$ at $10 \%(\mathrm{kPa})$ & $E_{\mathrm{s}}$ at $100 \%(\mathrm{kPa})$ & $E_{\mathrm{s}}$ at $300 \%(\mathrm{kPa})$ & $G^{\prime}$ at $1 \mathrm{~Hz}(\mathrm{kPa})$ \\
\hline$\alpha \mathrm{B} \alpha-74-23$ & $722.0 \pm 15.0$ & $504.1 \pm 38.4$ & $454.1 \pm 43.2$ & $282.9 \pm 6.4$ & $138.2 \pm 3.0$ & $182.9 \pm 11.1$ & 906.6 \\
\hline FIX-PRO® & $1762.5 \pm 165.1$ & $463.2 \pm 4.4$ & $230.3 \pm 46.2$ & $230.4 \pm 27.7$ & $138.7 \pm 6.5$ & $139.1 \pm 7.9$ & 158.4 \\
\hline
\end{tabular}


commercial PSA, FIX-PRO®. 7 specimens of FIX-PRO ${ }^{\circledR}$ with an average thickness of $0.923 \pm 0.038 \mathrm{~mm}$ were tested in the same way for comparison, showing comparable performance to the terpene material below $120 \%$ strain (Fig. 4 - squares). Tensile data for the individual specimens can be found in Fig. S6 and $\mathrm{S} 7, \dagger$ for $\alpha \mathrm{B} \alpha-74-23$ and FIX-PRO ${ }^{\circledR}$ respectively. On average, $\alpha \mathrm{B} \alpha-74-23$ exhibited a lower $\sigma_{\text {UTS }}$ than the commercial elastomer by a factor of 2.44 , but showed a slightly greater $\varepsilon_{\mathrm{UTS}}$, by a factor of 1.09. Owing to the non-linear nature of the tensile data for these elastomeric materials, a secant modulus $\left(E_{\mathrm{s}}\right)$ has been determined at 1\%, 10\%, 100\% and 300\% strain for the purpose of direct comparison between the stiffnesses of $\alpha \mathrm{B} \alpha-74-23$ and FIX-PRO ${ }^{\circledR}$, as provided in Table $6 . E_{\mathrm{S}}$ at $10 \%$ and $100 \%$ strains were found to be very similar in magnitude. At large strains, where $\varepsilon=300 \%$, a difference in stiffness of $23.9 \%$ was observed, with the $\alpha \mathrm{B} \alpha-74-23$ being stiffer than the FIX-PRO ${ }^{\circ}$. Based on these results, it can be concluded that under the degree of tensile deformations typically experienced during removal from a backing film and application to a surface, where strains are likely to be small; of the order of $<100 \%$, the terpene-based elastomer behaves sufficiently similarly to the benchmark commercial material to infer suitability to this target application.

At large strains, $\alpha \mathrm{B} \alpha-74-23$ exhibits a small degree of strain hardening, whereas the stiffness of FIX-PRO® remains approximately constant. The behaviour of both elastomers is in line with similar amorphous polymer systems. ${ }^{53,54}$ In order to better understand the large strain regime, a simple neoHookean model with finite extensibility, here implemented as a Gent model, ${ }^{55}$ was fitted to the data in parallel with a constant flow stress.

$$
\sigma=\frac{\sigma_{\mathrm{y}}}{\lambda}+G_{\mathrm{R}}\left(\lambda-\lambda^{-2}\right)\left(\frac{J_{\mathrm{m}}}{J_{\mathrm{m}}-\lambda^{2}-\frac{2}{\lambda}+3}\right)
$$

where $\sigma_{\mathrm{y}}$ is the flow (yield) stress, $\lambda$ is the stretch, $G_{\mathrm{R}}$ is the strain-hardening modulus, and $J_{\mathrm{m}}=\lambda_{\max }{ }^{2}+2 / \lambda_{\max }-3$, where $\lambda_{\max }$ is the limiting extensibility in uniaxial tension. A high quality of fit to the experimental data $\left(R^{2}>0.99\right)$ was achieved by the model, confirming its applicability, and producing the parameters provided in Table 7. The two materials exhibit similar $G_{\mathrm{R}}$, indicating a comparable density of network constraints, while $\lambda_{\max }$ values for $\alpha \mathrm{B} \alpha-74-23$ were on average $30 \%$ lower than for the commercial FIX-PRO®. In both cases flow stresses were found to be small.

Probe tack adhesion testing was carried out for 3 specimens of $\alpha \mathrm{B} \alpha-74-23$ and 5 specimens of FIX-PRO®, the results of which are presented in Table 6. Fig. 5 shows measurements of force during probe separation as a function of the

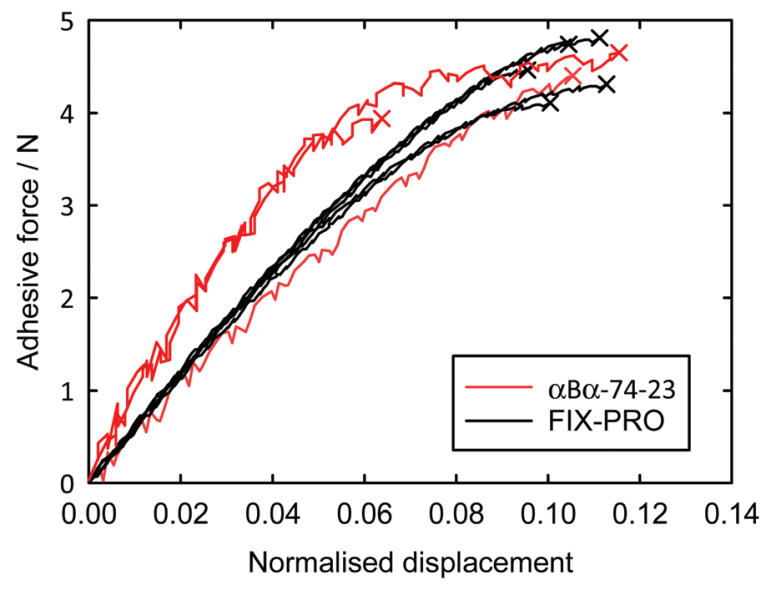

Fig. 5 Adhesive probe tack force as a function of displacement normalised by specimen thickness, for 3 specimens of $\alpha \mathrm{B} \alpha-74-23$ and for 5 specimens of FIX-PRO ${ }^{\circledR}$. Crosses indicate failure properties for both materials.

displacement normalised by thickness at $0 \mathrm{~N}$ loading for $\alpha \mathrm{B} \alpha-74-23$ and FIX-PRO®. A peak adhesive force of $4.33 \pm 0.21 \mathrm{~N}$ was observed for $\alpha \mathrm{B} \alpha-74-23$, which is comparable to that observed for the commercial material, with an average peak force of $4.49 \pm 0.13 \mathrm{~N}$. The actual displacement at peak force was found to be lower for $\alpha \mathrm{B} \alpha-74-23$ than for FIX-PRO ${ }^{\circledR}$, but when normalised by the specimen thickness, both materials exhibit similar adhesion behaviour. Representative force-displacement results for single specimens of $\alpha B \alpha-74-23$ and FIX-PRO ${ }^{\circledR}$ are also provided to full detachment in Fig. 6, showing complete failure of the adhesive bond. The work of adhesion was determined via numerical integration as $W=69.3$ and $39.5 \mathrm{~kJ} \mathrm{~m}^{-3}$ respectively for $\alpha \mathrm{B} \alpha-74-23$ and FIX-PRO ${ }^{\circledR}$. This indicates that almost double the energy is required to cause failure of the adhesive bond for the novel elastomer compared with the commercial material.

Dynamic shear measurements performed at $25^{\circ} \mathrm{C}$ on both materials showed no presence of an intersection in the elastic and viscous shear moduli within a frequency range of 0.01-10 $\mathrm{Hz}$, indicating that structural relaxation does not occur at typical adhesive application timescales when operating under ambient conditions. The elastic shear modulus $\left(G^{\prime}\right)$ was found to be greater for $\alpha \mathrm{B} \alpha-74-23$ than for FIX-PRO ${ }^{\circledR}$ by a factor of 5.72 at an oscillation frequency of $1 \mathrm{~Hz}$ (Table 6), showing some difference in the small-strain behaviour as indicated by the tensile measurements.

Whilst further investigation into the influence of adhesive dwell time, application force and substrate conditions are

Table 7 Modified Gent model fitting parameters obtained for $\alpha \mathrm{B} \alpha-74-23$ and FIX-PRO ${ }^{\circ}$ tensile result, where \pm denotes one standard error

\begin{tabular}{|c|c|c|c|c|c|}
\hline Material & $G_{\mathrm{R}}(\mathrm{kPa})$ & $\sigma_{\mathrm{y}}(\mathrm{kPa})$ & $J_{\mathrm{m}}$ & $\lambda_{\max }$ & $R^{2}$ \\
\hline$\alpha B \alpha-74-23$ & $68.3 \pm 1.4$ & $6.4 \pm 1.0$ & $16.9 \pm 1.2$ & $4.4 \pm 0.1$ & $0.9979 \pm 0.0006$ \\
\hline FIX-PRO® & $66.8 \pm 3.2$ & $13.6 \pm 1.8$ & $35.7 \pm 0.8$ & $6.2 \pm 0.1$ & $0.9987 \pm 0.0002$ \\
\hline
\end{tabular}




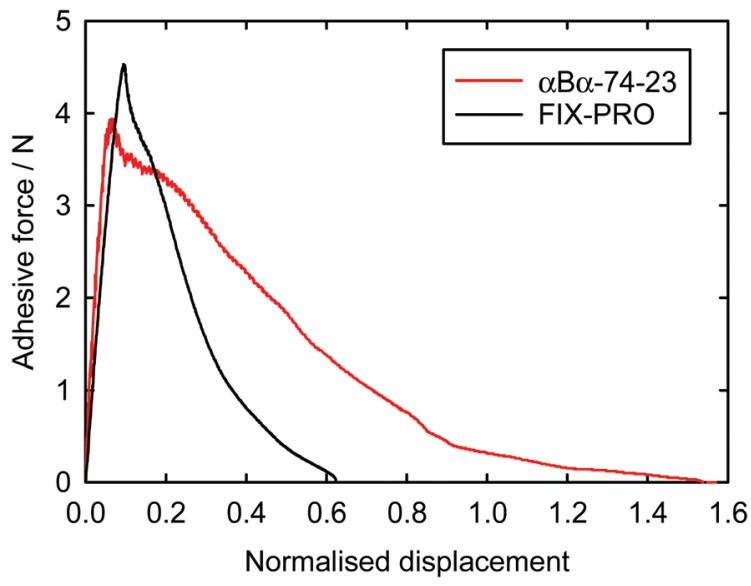

Fig. 6 Representative probe adhesion results for single specimens of $\alpha \mathrm{B} \alpha-74-23$ and FIX-PRO ${ }^{8}$ to full detachment. $W=69.3 \mathrm{~kJ} \mathrm{~m}^{-3}$ for $\alpha \mathrm{B} \alpha-74-23$, and $39.5 \mathrm{~kJ} \mathrm{~m}^{-3}$ for FIX-PRO ${ }^{\circledR}$ were determined from the areas under the curves.

required to verify specific application suitability, the findings based on these preliminary assessments are promising. The similarity of both tensile and adhesive properties between the terpene-derived material and a commercial PSA highlight the potential for these novel copolymers as renewable alternatives to existing oil-based adhesives.

\section{Conclusions}

A range of homopolymers and block copolymers of terpenederived (meth)acrylates have been synthesised via RAFT polymerisation. The pinene methacrylates were shown to polymerise well and act as macro-RAFT agents, while LiMA and the terpene acrylates were polymerised with varying degrees of RAFT control. Chain extension of these macro-RAFT agents with P $\beta$ PA and PLiA (extensions of 10-18 $000 \mathrm{~g} \mathrm{~mol}^{-1}$ ) were successful, with targeted molecular weights reached and reasonably low dispersities observed. Some loss of control was observed for longer PLiA chain extensions, and further work is required to establish full RAFT control. The difunctional, Z-connected RAFT agent, BDAT, was then employed to synthesise ABA triblock copolymers with the potential to act as TPEs and PSAs. This method was successfully used to synthesise P $\alpha$ PMA- $b$-PBuA- $b$-P $\alpha$ PMA triblock copolymers with reasonable dispersities in two steps. We have also begun to extend this method to include the additional monomers $\beta$ PMA and LiA, creating partially and fully renewable, terpene (meth)acrylate polymers, with varying levels of RAFT control achieved.

The morphologies of a number of P $\alpha$ PMA- $b$-PBuA- $b$-P $\alpha$ PMA triblock copolymers, at varying hard : soft polymer ratios, have been investigated. The material with the most promising structure was taken forward for further measurements, and was found to demonstrate good tensile properties and adhesive behaviour, comparable to a commercial PSA.

\section{Experimental}

\section{Materials}

Monomers $\alpha$ PMA and $\alpha$ PA were obtained from Cornelius Specialities and the inhibitor was removed from both via an alumina column prior to use. $\beta$-Pinene and limonene-based monomers were synthesised following a literature method. ${ }^{18}$ For monomers methyl methacrylate (MMA, 99\% ProSciTech) butyl acrylate (BuA, 99\% BASF), the inhibitor was removed via an alumina column prior to use. The RAFT agent, $S, S^{\prime}$-bis $\left(\alpha, \alpha^{\prime}-\right.$ dimethyl- $\alpha$ "-acetic acid)-trithiocarbonate (BDAT), was synthesised following a literature method. ${ }^{64}$ 2,2-Azobis(2-methylpropionitrile) (AIBN, 98\% Sigma Aldrich) was recrystallised twice before use. All other reagents were purchased from Sigma-Aldrich and used as purchased. Details can be found in the ESI. $\dagger$

\section{Characterisation}

Nuclear Magnetic Resonance $\left({ }^{1} \mathrm{H}\right.$ NMR) spectra were obtained on a Bruker Avance III HD $400 \mathrm{MHz}$. Samples were dissolved in deuterated chloroform $\left(\mathrm{CDCl}_{3}\right)$.

\section{Gel permeation chromatography}

Gel permeation chromatography (GPC) was used to acquire molecular weight and dispersity data for the polymers. An Agilent 1260 infinity multidetector SEC system, with a multi angle light scattering detector (MALS, Wyatt, Optilab Dawn ${ }^{+}+$), was coupled to a Viscometer (Wyatt, ViscoStar-2) and a differential refractometer (DRI, Agilent 1260) for sample detection. The columns used were $2 \times$ Agilent PLGEL $5 \mu \mathrm{m}$ Mixed D $(7.5 \mathrm{~mm} \times 300 \mathrm{~mm})$ and a PLGEL $5 \mu \mathrm{m}$ guard column $(7.5 \mathrm{~mm} \times 50 \mathrm{~mm})$. The mobile phase was THF at $1 \mathrm{~mL} \mathrm{~min}{ }^{-1}$ at $40{ }^{\circ} \mathrm{C}$. A known refractive index increment $(\mathrm{d} n / \mathrm{d} c)$ value of $0.067 \mathrm{~mL} \mathrm{~g}^{-1}$ was used for PBuA. ${ }^{65}$

$\mathrm{d} n / \mathrm{d} c$ values were measured for the poly(terpene(meth)acrylates) and were as follows: P $\alpha$ PMA - $0.106 \mathrm{~g} \mathrm{~mol}^{-1}, \mathrm{P} \beta \mathrm{PMA}-$ $0.107 \mathrm{~mL} \mathrm{~g}^{-1}, \mathrm{PLiA}-0.085 \mathrm{~mL} \mathrm{~g}^{-1}$, PBuA - $0.084 \mathrm{~mL} \mathrm{~g}^{-1}$. For block copolymers, the $\mathrm{d} n / \mathrm{d} c$ was determined using the following equation: ${ }^{26}$

$$
\frac{\mathrm{d} n}{\mathrm{~d} c}(\mathrm{P} 1-b-\mathrm{P} 2)_{(\mathrm{P} 1)} \frac{\mathrm{d} n}{\mathrm{~d} c}(\mathrm{P} 1)+m_{(\mathrm{P} 2)} \frac{\mathrm{d} n}{\mathrm{~d} c}(\mathrm{P} 2)
$$

A standard column calibration $(12 \times$ PMMA standards across a range of $M_{\mathrm{n}}=1000-400000 \mathrm{~g} \mathrm{~mol}^{-1}$ ) was used to calculate the molecular weights of PMMA and PMMA-based homopolymers. The $\mathrm{d} n / \mathrm{d} c$ value of LiMA was not found, so PLiMA was also compared to PMMA standards. All polymers below $10000 \mathrm{~g} \mathrm{~mol}^{-1}$ were compared to PMMA standards, as below this length the light scattering data are less accurate. P $\alpha$ PMA homopolymers were measured by comparison with PMMA standards, as the values obtained from light scattering were inconsistent.

Dynamic Mechanical Analysis (DMA) was carried out on a Triton Technology DMA (TTDMA) (now Mettler Toledo DMA1) using the powder pocket accessory. Approximately $40 \mathrm{mg}$ of 
sampled was added to the powder pocket and measured at 1 and $10 \mathrm{~Hz}$ in single cantilever bending geometry between -100 to $250^{\circ} \mathrm{C}$, or a narrower temperature window, depending on the region of interest. $T_{\mathrm{g}}$ values were taken from the peak in the $\tan \delta$ curve at $1 \mathrm{~Hz}$.

Atomic Force Microscopy (AFM) measurements were conducted on a Dimension FastScan AFM (Bruker Corporation), working in PeakForce quantitative nanomechanical property (PF-QNM) mode in air with an RTESPA-150 silicon probe (spring constant $=2.44 \mathrm{~N} \mathrm{~m}^{-1}$ ) Samples were prepared by dissolving $30 \mathrm{mg}$ of polymer in $1 \mathrm{~mL}$ of toluene, then spin coating the solution onto a silicon wafer at $1500 \mathrm{rpm}$ for $30 \mathrm{~s}$. The resulting thin films were annealed at $180{ }^{\circ} \mathrm{C}$ for 24 hours, after which the oven was turned off and allowed to cool slowly to room temperature.

Free Polymer Films were prepared by solution casting circa $20 \mathrm{wt} \%$ solutions of polymer in THF onto an ETFE frame. An amount of approximately $1 \mathrm{~g}$ of polymer was used per $10 \mathrm{~cm}^{2}$ of the ETFE frame, as this was found to give a film thickness of around $0.5 \mathrm{~mm}$, which was suitable for mechanical testing. The frame and solution were covered with foil, and the solvent was allowed to evaporate over 24 hours. The frame and polymer were placed in a vacuum oven at $25{ }^{\circ} \mathrm{C}$ for at least 3 days to remove all traces of solvent.

Small-Angle X-ray Scattering (SAXS) analyses were performed on copolymer films prepared via solvent casting from solutions $(20 \mathrm{wt} \%)$ in THF. SAXS patterns were recorded at a synchrotron source (Diamond Light Source, station I22, Didcot, UK) using monochromatic X-ray radiation (X-ray wavelength $\lambda=0.999 \AA$, with scattering vector $q$ ranging from 0.003 to $0.25 \AA^{-1}$, where $q=4 \pi \sin \theta / \lambda$ and $\theta$ is one-half of the scattering angle) and a 2D Pilatus $2 \mathrm{M}$ pixel detector (Dectris, Switzerland). Scattering data were reduced utilising standard routines available at the beamline. ${ }^{66}$

\section{Mechanical testing}

The dried films were peeled off the ETFE sheet, and cut into strips of $5 \times 25 \mathrm{~mm}^{2}$ using a pair of parallel razor blades for the purpose of tensile testing, or into an $8 \mathrm{~mm}$ diameter disc using a steel punch for the purpose of probe adhesion testing or rheometry. Specimens dimensions were determined using a combination of thickness gauge measurements and optical scanning followed by Image analysis. All mechanical and rheological testing was carried out using an MCR302 Anton Paar rheometer.

Dynamic shear rheometry was conducted using an $8 \mathrm{~mm}$ diameter parallel plate measuring system and temperaturecontrolled CTD450 oven coupled to a water recirculation cooling unit. Specimens were subjected to a compressive normal force of $25 \mathrm{~N}$ for 5 minutes to ensure full contact with the measuring plates, prior to commencing an isothermal frequency scan across $0.01-10 \mathrm{~Hz}$ at a strain amplitude of $0.1 \%$ under fixed gap conditions, maintaining contact between the specimen and plates.

For the purpose of tensile testing, a twin-drum Sentmanat Extensional Rheometry (SER) fixture with a fixed distance of
$12.72 \mathrm{~mm}$ between the drums was employed in conjunction with the rheometer, applying a true strain rate of $0.03 \mathrm{~s}^{-1}$ until specimen failure. For adhesion probe experiments, an Anton Paar disposable aluminium rheometry plate with an average surface roughness of $R_{\mathrm{a}}=0.8 \mu \mathrm{m}$ was machined to a diameter of $5.8 \mathrm{~mm}$. The probe was fixed to the rheometer measuring system and brought into contact with the elastomer at a speed of $10 \mu \mathrm{m} \mathrm{s}^{-1}$ until a normal force of $10 \mathrm{~N}$ was registered. The $10 \mathrm{~N}$ force was maintained for 1 minute, then the probe was retracted at a speed of $1.25 \mu \mathrm{m} \mathrm{s}^{-1}$ until the peak adhesive force was achieved. All mechanical testing was carried out at room temperature $\left(22.56 \pm 0.36{ }^{\circ} \mathrm{C}\right)$.

\section{RAFT homopolymerisations}

The RAFT agent, 2-cyano-2-propyl dodecyl trithiocarbonate (CPDT) (varying mol\%) and AIBN ( $0.2 \mathrm{~mol} \%$ of CPDT) were completely dissolved in toluene $(1 \mathrm{~mL})$, with the required monomer $(1 \mathrm{~g})$. The oxygen was removed from the reaction mixture via 3 freeze-pump-thaw cycles. The reaction mixture was then heated to $65{ }^{\circ} \mathrm{C}\left(75^{\circ} \mathrm{C}\right.$ for $\alpha$ PMA polymerisation where stated) for $24 \mathrm{~h}$ or until the desired conversion was reached. The reaction was terminated by exposure to air and the resultant polymers were purified by dissolving the reaction mixture in a minimum of THF and precipitating into ice cold methanol, filtered using Buchner filtration and dried in a vacuum oven. The reaction was monitored via ${ }^{1} \mathrm{H}$ NMR, and the resultant polymers were analysed by ${ }^{1} \mathrm{H}$ NMR, GPC and DMA.

\section{Block copolymer synthesis via RAFT}

A series of macro-RAFT agents were synthesised via the homopolymerisation method described above. The macro-RAFT agent polymerisations were terminated below $60 \%$ conversion to retain chain end fidelity. The reactions were monitored using ${ }^{1} \mathrm{H}$ NMR and when nearing $60 \%$ conversion, the reaction mixture was exposed to air, quenching the radicals and terminating the reaction. Ratios of macro-RAFT agent to monomer were determined by the required molecular weight of the second block. A representative procedure was as follows: limonene acrylate $(0.125 \mathrm{~g}, 0.6 \mathrm{mmol}), \mathrm{P} \alpha \mathrm{PMA}$ macro-RAFT agent (0.5 g, $0.0179 \mathrm{mmol}$ ) and AIBN (0.9 mg, $0.00357 \mathrm{mmol}$ ) were dissolved in toluene $(3 \mathrm{~mL})$ and transferred to a Schlenk tube. The reaction mixture underwent $3 \times$ freeze-pump-thaw cycles to remove any oxygen and was then heated to $65^{\circ} \mathrm{C}$. The reaction was monitored with ${ }^{1} \mathrm{H}$ NMR and terminated at $>95 \%$ conversion. The resultant P $\alpha$ PMA- $b$-PLiA block copolymer was purified via precipitation from THF into ice cold methanol.

When synthesising triblock copolymers, the macro-RAFT agent synthesis was carried out on a $\times 5$ scale, using BDAT as a difunctional RAFT agent. As a result of this scale up 2-3 precipitation steps were required to remove all unreacted monomer. The chain extensions were then carried out as for the diblock copolymers. The final triblock copolymers were analysed with ${ }^{1} \mathrm{H}$ NMR, GPC and DMA, and in some cases AFM and SAXS. 


\section{Conflicts of interest}

There are no conflicts to declare.

\section{References}

1 R. A. Sheldon, Green Chem., 2014, 16, 950-963.

2 M. R. Thomsett, R. A. Stockman, T. E. Storr, S. M. Howdle and O. R. Monaghan, Green Mater., 2016, 4, 115-134.

3 J. Hilschmann and G. Kali, Eur. Polym. J., 2015, 73, 363373.

4 N. Bauer, J. Brunke and G. Kali, ACS Sustainable Chem. Eng., 2017, 5, 10084-10092.

5 A. L. Li, X. Y. Wang, H. Liang and J. Lu, React. Funct. Polym., 2007, 67, 481-488.

6 Y. Wang, A.-L. Li, H. Liang and J. Lu, Eur. Polym. J., 2006, 42, 2695-2702.

7 A. L. Li, X. Y. Wang, H. Liang and J. Lu, J. Polym. Sci., Part A: Polym. Chem., 2009, 47, 5954-5966.

8 M. Matsuda, K. Satoh and M. Kamigaito, J. Polym. Sci., Part A: Polym. Chem., 2013, 51, 1774-1785.

9 J. Li, J. El Harfi, S. M. Howdle, K. Carmichael and D. J. Irvine, Polym. Chem., 2012, 3, 1495-1501.

10 K. Adlington, J. El Harfi, J. Li, K. Carmichael, J. A. Guderian, C. B. Fox and D. J. Irvine, Biomacromolecules, 2016, 17, 165-172.

11 H. C. Quilter, M. Hutchby, M. G. Davidson and M. D. Jones, Polym. Chem., 2017, 8, 833-837.

12 J. R. Lowe, M. T. Martello, W. B. Tolman and M. A. Hillmyer, Polym. Chem., 2011, 2, 702-708.

13 N. Oberleitner, A. K. Ressmann, K. Bica, P. Gärtner, M. W. Fraaije, U. T. Bornscheuer, F. Rudroff and M. D. Mihovilovic, Green Chem., 2017, 19, 1-5.

14 O. Hauenstein, M. Reiter, S. Agarwal, B. Rieger and A. Greiner, Green Chem., 2016, 18, 760-770.

15 M. Claudino, J.-M. Mathevet, M. Jonsson and M. Johansson, Polym. Chem., 2014, 5, 3245-3260.

16 M. Firdaus, L. Montero De Espinosa and M. A. R. Meier, Macromolecules, 2011, 44, 7253-7262.

17 M. Firdaus and M. A. R. Meier, Green Chem., 2013, 15, 370380.

18 M. F. Sainz, J. A. Souto, D. Regentova, M. K. G. Johansson, S. T. Timhagen, D. J. Irvine, P. Buijsen, C. E. Koning, R. A. Stockman and S. M. Howdle, Polym. Chem., 2016, 7, 2882-2887.

19 M. A. Droesbeke and F. E. Du Prez, ACS Sustainable Chem. Eng., 2019, 7, 11633-11639.

20 T. Castagnet, G. Aguirre, J. M. Asua and L. Billon, ACS Sustainable Chem. Eng., 2020, 8, 7503-7512.

21 D. J. Keddie, Chem. Soc. Rev., 2014, 43, 496-505.

22 R. T. A. Mayadunne, J. Jeffery, G. Moad and E. Rizzardo, Macromolecules, 2003, 36, 1505-1513.

23 N. Bensabeh, A. Moreno, A. Roig, O. R. Monaghan, J. C. Ronda, V. Cádiz, M. Galià, S. M. Howdle, G. Lligadas and V. Percec, Biomacromolecules, 2019, 20, 2135-2147.
24 N. Bensabeh, J. C. Ronda, M. Galià, V. Cádiz, G. Lligadas and V. Percec, Biomacromolecules, 2018, 19, 1256-1268.

25 S. Noppalit, A. Simula, N. Ballard, X. Callies, J. M. Asua and L. Billon, Biomacromolecules, 2019, 20, 2241-2251.

26 S. Noppalit, A. Simula, L. Billon and J. M. Asua, Polym. Chem., 2020, 11, 1151-1160.

27 U. Montanari, V. Taresco, A. Liguori, C. Gualandi and S. M. Howdle, Polym. Int., 2021, 70, 499-505.

28 R. K. Bose, M. Enke, A. M. Grande, S. Zechel, F. H. Schacher, M. D. Hager, S. J. Garcia, U. S. Schubert and S. van der Zwaag, Eur. Polym. J., 2017, 93, 417-427.

29 J. H. Yang, B. C. Chun, Y. C. Chung and J. H. Cho, Polymer, 2003, 44, 3251-3258.

30 S. Keki, C. Bogacs, L. Bogacs, L. Daroczi and M. Zsuga, Angew. Makromol. Chemie, 1997, 245, 183-191.

31 J. Markarian, Plast. Addit. Compd., 2004, 6, 46-49.

32 W. Wang, W. Lu, A. Goodwin, H. Wang, P. Yin, N. G. Kang, K. Hong and J. W. Mays, Prog. Polym. Sci., 2019, 95, 1-31.

33 J. Shin, M. T. Martello, M. Shrestha, J. E. Wissinger, W. B. Tolman and M. A. Hillmyer, Macromolecules, 2011, 44, 87-94.

34 RAFT: Choosing the right agent to achieve controlled polymerization, Sigma Aldrich, http://www.sigmaaldrich. com/technical-documents/articles/materials-science/ polymer-science/raft-polymerization.html, (accessed June 2020).

35 S. Perrier, Macromolecules, 2017, 50, 7433-7447.

36 M. J. Darabi Mahboub, J. L. Dubois, F. Cavani, M. Rostamizadeh and G. S. Patience, Chem. Soc. Rev., 2018, 47, 7703-7738.

37 D. M. O'Brien, R. L. Atkinson, R. Cavanagh, A. A. C. Pacheco, R. Larder, E. Krumins, A. J. Haddleton, C. Alexander, R. A. Stockman, S. M. Howdle and V. Taresco, Eur. Polym. J., 2020, 125, 109516.

38 M. F. Sainz, PhD thesis, University of Nottingham, 2016.

39 D. J. Keddie, G. Moad, E. Rizzardo and S. H. Thang, Macromolecules, 2012, 45, 5321-5342.

40 D. J. Keddie, Chem. Soc. Rev., 2014, 43, 496-505.

41 G. Gody, T. Maschmeyer, P. B. Zetterlund and S. Perrier, Nat. Commun., 2013, 4, 2505.

42 G. Gody, T. Maschmeyer and P. B. Zetterlund, Macromolecules, 2014, 47, 639-649.

43 A.-V. Ruzette and L. Leibler, Nat. Mater., 2005, 4, 19-31.

44 T. G. Fox, Bull. Am. Phys. Soc., 1956, 1, 123.

45 R. J. Spontak and N. P. Patel, Curr. Opin. Colloid Interface Sci., 2000, 5, 333-340.

46 L. G. Williams, K. Sullivan and J. Tsanaktsidis, Select RAFT Agents for Making Well-Defined Functionalized Polymers, https:/www.sigmaaldrich.com/technical-documents/articles/ technology-spotlights/raft-agents-for-functionalized-polymers. html (accessed March 2021).

47 J. Ma and H. Zhang, Macromol. Res., 2014, 23, 67-73.

48 Y. Luo, X. Wang, Y. Zhu, B. G. Li and S. Zhu, Macromolecules, 2010, 43, 7472-7481.

49 S. Wang, L. Shuai, B. Saha, D. G. Vlachos and T. H. Epps, ACS Cent. Sci., 2018, 4, 701-708. 
50 X. Fu, Y. Yuan, X. Chen, Y. Xiao, J. Wang, C. Zhou and J. Lei, J. Appl. Polym. Sci., 2017, 134, 1-7.

51 G. Holden, in Encyclopedia of Polymer Science and Technology, John Wiley \& Sons, Inc., Hoboken, NJ, United States, 2010.

52 W. Lu, Y. Wang, W. Wang, S. Cheng, J. Zhu, Y. Xu, K. Hong, N. G. Kang and J. Mays, Polym. Chem., 2017, 8, 5741-5748.

53 C. C. W. J. Clarijs and L. E. Govaert, J. Polym. Sci., Part B: Polym. Phys., 2019, 57, 1001-1013.

54 S. Bahadur, Polym. Eng. Sci., 1973, 13, 266-272.

55 A. N. Gent, Rubber Chem. Technol., 1996, 69, 59-61.

56 R. Vendamme, N. Schüwer and W. Eevers, J. Appl. Polym. Sci., 2014, 131, 8379-8394.

57 N. Karyu, M. Noda, S. Fujii, Y. Nakamura and Y. Urahama, J. Appl. Polym. Sci., 2016, 43639, 1-11.

58 X. Zhang, H. Liu, L. Yue, Y. Bai and J. He, Polym. Bull., 2019, 76, 3093-3112.
59 S. S. Baek and S. H. Hwang, Eur. Polym. J., 2017, 92, 97104.

60 K. Y. Cho, A. Cho, H. J. Kim, S. H. Park, C. M. Koo, Y. J. Kwark, H. G. Yoon, S. S. Hwang and K. Y. Baek, Polym. Chem., 2016, 7, 7391-7399.

61 M. A. Droesbeke, A. Simula, J. M. Asua and F. E. Du Prez, Green Chem., 2020, 22, 4561-4569.

62 S. C. Temin, in Handbook of Adhesives, ed. I. Skeist, Springer US, Boston, MA, 3rd edn, 1990, pp. 641-633.

63 NPCS Board of Consultants \& Engineers, in The Complete Book on Adhesives, Glues \& Resins Technology, 2016, pp. 146-175.

64 J. T. Lai, D. Filla and R. Shea, Macromolecules, 2002, 35, 6754-6756.

65 S. Mori and H. G. Barth, Size Exclusion Chromatography, Springer Berlin Heidelberg, New York, 1999.

66 B. R. Pauw, A. J. Smith, T. Snow, N. J. Terrill and A. F. Thünemann, J. Appl. Crystallogr., 2017, 50, 1800-1811. 